On the right side, size reduction usually involves peripheral wedge resection or middle or upper lobectomy, but not lower lobectomy. For anatomic reasons, the right lower lobe is more vulnerable to atelectasis, accumulation of secretions, and infections; this represents a common finding in a donor with a long intubation period. Thus, when a donor is marginal because of a compromised right lower lobe with expected size mismatch and necessity of a size-reduction procedure, the lung is either discarded or the size reduction will be at the expense of the healthier upper and middle lobes.

It is well known that postlobectomy bronchopleural fistula is more frequent after lower lobectomy than other types of resection. ${ }^{5}$ This may be due to the dependent position of the bronchial stump with more exposure to secretions and decreased retrograde blood flow from the surrounding lung parenchyma. In transplant recipients, the situation is further compromised with the use of immunosuppressive drugs, corticosteroids, and, possibly, prolonged mechanical ventilation. Consequently, the presence of 2 bronchial suture lines in a transplant recipient is a real threat. This may be the reason to avoid performing a lower lobectomy to reduce the size of the donor lung. With our technique, we avoided the pres- ence of 2 bronchial suture lines, a dependent bronchial stump, and the risk of postlobectomy bronchopleural fistula.

\section{CONCLUSIONS}

We consider this technique an addendum to the armamentarium of thoracic surgeons as a size-reduction procedure and a method of increasing the pool of donor lungs.

\section{References}

1. Aigner C, Mazhar S, Jaksch P, Seebacher G, Taghavi S, Marta G, et al. Lobar transplantation, split lung transplantation and peripheral segmental resection-reliable procedures for downsizing donor lungs. Eur J Cardiothorac Surg. 2004;25: 179-83.

2. Santos F, Lama R, Alvarez A, Algar FJ, Quero F, Cerezo F, et al. Pulmonary tailoring and lobar transplantation to overcome size disparities in lung transplantation. Transplant Proc. 2005;37:1526-9.

3. Couetil JP, Tolan MJ, Loulmet DF, Guinvarch A, Chevalier PG, Achkar A, et al. Pulmonary bipartitioning and lobar transplantation: a new approach to donor organ shortage. J Thorac Cardiovasc Surg. 1997;113:529-37.

4. Artemiou O, Birsan T, Taghavi S, Eichler I, Wisser W, Wolner E, et al. Bilateral lobar transplantation with the split lung technique. J Thorac Cardiovasc Surg. 1999; 118:369-70.

5. Sirbu H, Busch T, Aleksic I, Schreiner W, Oster O, Dalichau H. Bronchopleura fistula in the surgery of non-small cell lung cancer: incidence, risk factors, and management. Ann Thorac Cardiovasc Surg. 2001;7:330-6.

\title{
Two-stage operation for an extensive infected aortic arch
}

\author{
Masakazu Nakao, MD, MRCS, Yeong Phang Lim, MBBS, FRCS, FAMS, Martin John Jarmin III MD, \\ Boon Hean Ong, MBBS, MRCS, and Yeow Leng Chua, MBBS, FRCS, FAMS, Singapore
}

The optimal management of an extensive infection involving the aortic arch is not well defined. We report the use of a 2-stage operation that consists of an ascending aorta-descending aorta bypass through a median sternotomy followed by a total exclusion of the infected aortic arch with debridement of infected tissue through a left posterolateral thoracotomy.

\section{CLINICAL SUMMARY}

A 68-year-old man with hypertension and diabetes mellitus presented with fever associated with dysphagia and

\footnotetext{
From the Department of Cardiothoracic Surgery, National Heart Centre, Singapore. Disclosures: None.

Received for publication Feb 1, 2009; revisions received April 16, 2009; accepted for publication April 30, 2009; available ahead of print June 15, 2009.

Address for reprints: Masakazu Nakao, MD, MRCS, National Heart Centre, Singapore, Department of Cardiothoracic Surgery, Mistri Wing, 17 Third Hospital

Ave, Singapore 168752 (E-mail: masakazu.nakao@singhealth.com.sg).

J Thorac Cardiovasc Surg 2010;139:1073-5

$0022-5223 / \$ 36.00$

Copyright (C) 2010 by The American Association for Thoracic Surgery

doi:10.1016/j.jtcvs.2009.04.038
}

hoarseness of voice, as well as chest pain radiating to the back for a week. Computed tomographic analysis of the thorax revealed a distal aortic arch pseudoaneurysm $7.3 \mathrm{~cm}$ in diameter and air within the aortic wall (Figure 1). Blood cultures grew Salmonella enteriditis.

The patient underwent emergency surgical intervention. Intraoperatively, the pseudoaneurysm was also noted to involve the proximal aortic arch, including the roots of all 3 major branches. An ascending aorta-descending aorta bypass through a median sternotomy was performed to exclude the aortic arch and the proximal descending thoracic aorta. The left common femoral artery, right brachiocephalic artery, and right atrium were cannulated. The heart was displaced superiorly out of the pericardium by using the Urchin heart positioning device (Medtronic, Inc, Minneapolis, Minn) with full cardiopulmonary bypass, and the distal descending aorta was accessed through a longitudinal incision in the posterior pericardium. A $20-\mathrm{mm}$ woven Dacron graft was anastomosed to the distal descending thoracic aorta in a side-to-end fashion. The graft was tunneled proximally posterior to the inferior vena cava and brought up to 


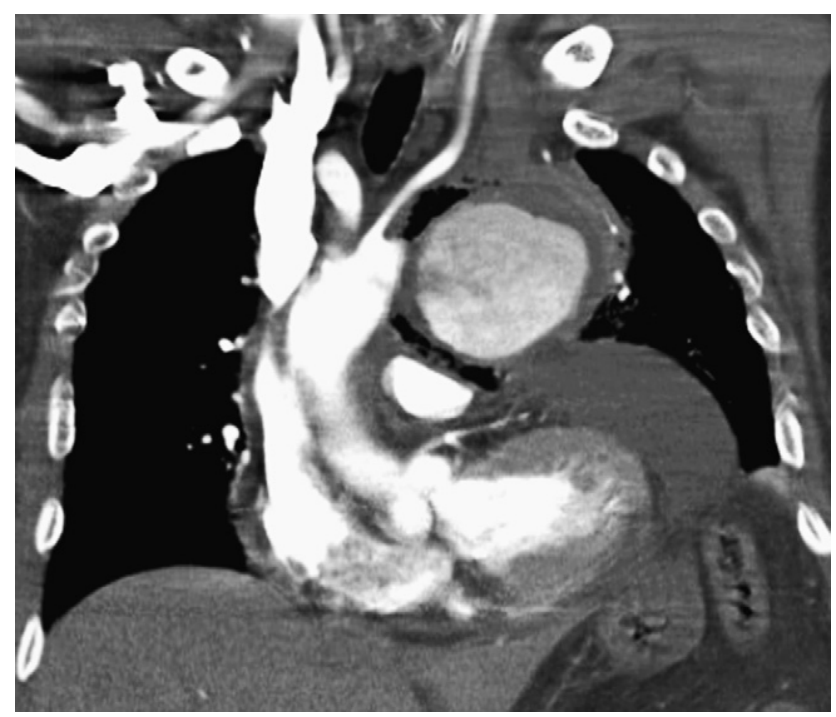

FIGURE 1. A preoperative computed tomographic scan of the thorax showed a distal aortic arch pseudoaneurysm and air within the aortic wall.

the right side of the ascending aorta and anastomosed in a side-to-end fashion. The descending aorta proximal to the distal anastomosis was interrupted with an Echelon 60 Endopath Stapler (Ethicon Endo-Surgery, Inc, Cincinnati, Ohio) at the level of T7. A 14-mm trouser graft was then anastomosed to this ascending aortic graft. One leg of the trouser graft was joined to the left carotid artery, whereas the other leg was connected to the right brachiocephalic artery. The native left carotid and right brachiocephalic arteries were ligated proximal to the anastomoses. Meanwhile, the left subclavian artery was ligated, and the ascending aorta distal to the aortic graft was obliterated.

Four days later, an aortogram showed residual flow from the ascending aorta to the aortic arch and left carotid artery. The median sternotomy was reopened to re-exclude the aorta and left carotid artery, after which transesophageal echocardiographic analysis confirmed no residual flow.

The large pseudoaneurysm of the distal arch with an area of rupture on the inferior wall was explored through a left posterolateral thoracotomy. The aorta was opened at the aortic arch, and then the left subclavian artery was oversewn from inside. Brisk backflow from the intercostal arteries was observed before they were oversewn. The mycotic pseudoaneurysm was evacuated and debrided, followed by copious lavage.

The patient recovered well. He underwent injection laryngoplasty for his hoarseness of voice and was discharged 43 days after the first operation. A computed tomographic aortogram performed 6 months after discharge showed a completely excluded aortic arch and descending aorta. Cotrimoxazole was given to the patient for 6 months after the operation, and he was well at follow-up 8 months after discharge.

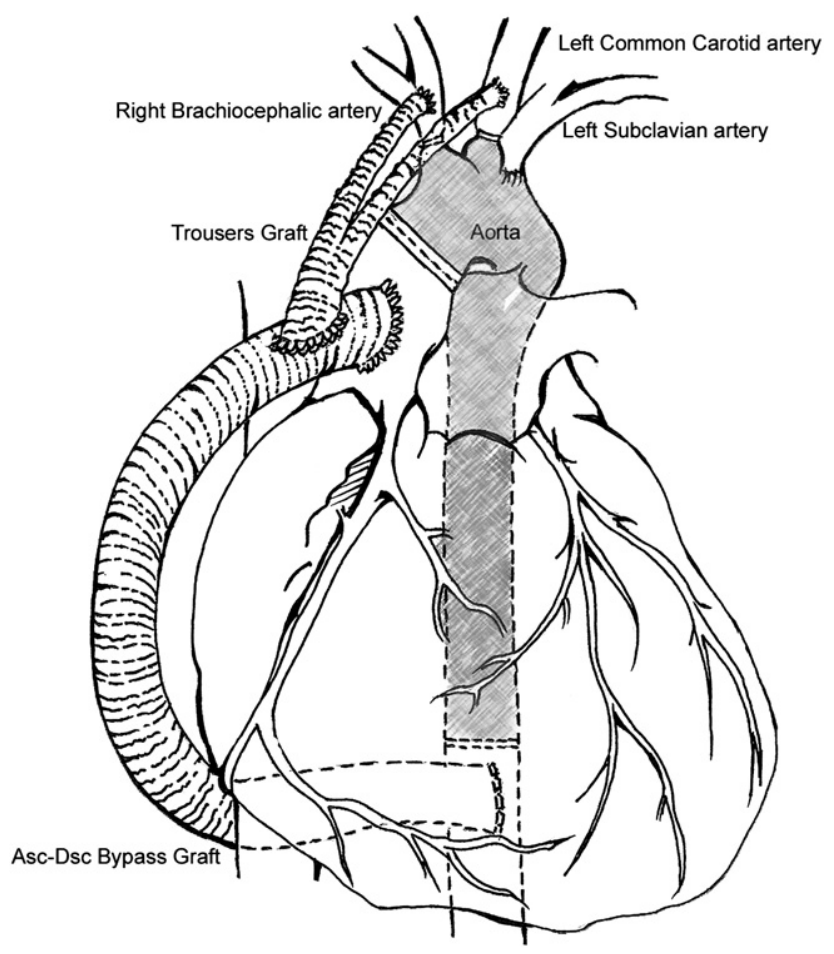

FIGURE 2. Ascending aorta-descending aorta bypass with a trouser graft to the right brachiocephalic artery and the left common carotid artery is shown. The shaded area shows the excluded aortic arch and descending thoracic aorta. Asc-Dsc, Ascending aorta-descending aorta.

\section{DISCUSSION}

The treatment of mycotic aortic aneurysms is a challenge for cardiothoracic surgeons, with high reported in-hospital mortality rates ranging from $16 \%$ to $44 \%$. Although a small number of successes have been previously reported with in situ graft replacement alone, the principles of treatment in an extensive infection consist of not only the establishment of extra-anatomic circulation but also the evacuation and debridement of all infected tissue. ${ }^{1,2}$

In this case we performed a 2-stage operation to accomplish the abovementioned principles. A similar 2-stage procedure was reported by Aizawa and colleagues, ${ }^{3}$ but in our patient we used an additional trouser graft to exclude the root of all 3 major branches in view of the extensive infection involving the proximal aortic arch.

In conclusion, an extra-anatomic ascending aorta-descending aorta bypass through a median sternotomy was first performed to avoid exposing the graft to the area of infection, as well as to establish a new circulation that excluded the infected aorta. This was followed by a left thoracotomy and complete evacuation of the extensive infection, which not only involved the aortic arch but also all 3 major branches. The second stage was only performed after the patient recovered sufficiently from the first operation. The advantage of this 2 -stage procedure is that by removing all 
infected tissue, we avoided having to administer lifelong antibiotics to the patient.

\section{References}

1. Hsu RB, Lin FY. Surgery for infected aneurysm of the aortic arch. $J$ Thorac Cardiovasc Surg. 2007;134:1157-62.
2. Fillmore AJ, Valentine RJ. Surgical mortality in patients with infected aortic aneurysms. J Am Coll Surg. 2003;196:435-41.

3. Aizawa K, Ohki S, Konishi H, Misawa Y. Extraanatomical ascending-abdominal aorta bypass with stump closure for aortic graft infection. Interact Cardiovasc Thorac Surg. 2008;7:646-7.

\title{
A simple method for the quantification and correction of aortic cusp prolapse by means of free margin plication
}

\author{
Munir Boodhwani, MD, MMSc, Laurent de Kerchove, MD, David Glineur, MD, and \\ Gebrine El Khoury, MD, Brussels, Belgium
}

Cusp prolapse is a common contributor to aortic insufficiency, occurring in $35 \%$ of patients undergoing aortic valve repair or valve-sparing surgery, ${ }^{1}$ and can be corrected by using a variety of surgical techniques, including free margin plication, triangular resection, and free margin resuspension. ${ }^{2-4}$ Although techniques for cusp prolapse assessment have been proposed, ${ }^{5}$ quantification of the degree of cusp prolapse can often be challenging, with the risk of undercorrection leaving residual prolapse or overcorrection leading to cusp restriction. We describe a simple method for the simultaneous quantification and correction of excess cusp tissue by means of free margin plication in the setting of a trileaflet aortic valve cusp prolapse.

\section{OPERATIVE TECHNIQUE}

A transverse aortotomy is performed $1 \mathrm{~cm}$ above the sinotubular junction, traction sutures are placed at the 3 commissures, and the distal aorta is retracted cephalad.

\section{Valve Assessment}

First, axial traction (perpendicular to the annular plane) is applied on the commissural sutures, which demonstrates the physiologic aortic valve closure position, and the area and height of coaptation can be observed. A prolapsing cusp will typically exhibit a transverse fibrous band at this time (Figure 1, A). Next, radial traction (parallel to the annular plane) is applied to the 3 commissural sutures, and the center of the cusp free margin can then be gently pushed down to-

\footnotetext{
From the Department of Cardiovascular and Thoracic Surgery Cliniques Universitaires Saint-Luc, Brussels, Belgium.

Disclosures: None.

Received for publication Feb 19, 2009; revisions received April 8, 2009; accepted for publication April 29, 2009; available ahead of print June 29, 2009.

Address for reprints: Munir Boodhwani, MD, MMSc, Service de Chirurgie Cardiovasculaire et Thoracique, Cliniques Universitaires Saint-Luc UCL 90, Avenue Hippocrate 10, Brussels B-1200, Belgium (E-mail: mboodhwani@ottawaheart.ca).

J Thorac Cardiovasc Surg 2010;139:1075-7

$0022-5223 / \$ 36.00$

Copyright (c) 2010 by The American Association for Thoracic Surgery

doi:10.1016/j.jtcvs.2009.04.037
}

ward the left ventricle with a forceps. A nonprolapsing cusp will remain at its physiologic coaptation level (halfway between the base of the cusp and its maximal height at the commissure), whereas a prolapsing cusp will be able to be pushed lower because of excessive cusp tissue.

\section{Free Margin Plication: Quantification and Repair}

A 7-0 polypropylene suture is passed through the center of the 2 nonprolapsing reference cusps, and gentle axial traction is applied (Figure 1, B). The prolapsing cusp is gently pulled parallel to the reference cusp, and a 6-0 polypropylene suture is passed through the prolapsing cusp from the aortic to ventricular side at the point at which it meets the center of the reference cusp (Figure 2, $A$ ). Next, the direction of traction on the prolapsing cusp is reversed, and the same suture is passed from the ventricular to the aortic side of the cusp, where it meets the middle of the reference cusp (Figure 2, $B$ ). The length of cusp free margin between the 2 ends of this 60 suture represents the quantity of excess free margin, which is then plicated by tying this suture with the excess tissue on the aortic side (Figure 2, $C$ ).

The plication is extended by about 5 to $10 \mathrm{~mm}$ onto the body of the aortic cusp by adding interrupted or running locked 6-0 polypropylene sutures (Figure 2, D). If there is significant excessive tissue, it can be shaved off with a scalpel or scissors, keeping sufficient tissue to bring the edges together.

\section{Technical Adjuncts}

When 2 cusps are prolapsing, a 7-0 suture is passed through the center of the third reference cusp. An adjacent prolapsing cusp is then pulled parallel to the reference cusp, and the 6-0 suture is passed through the free margin at the point at which it meets the center of the reference cusp. Next, taking advantage of symmetry, the suture is passed back through the cusp an equivalent distance from the cusp center on the other side. This then represents the amount of excess cusp tissue and is plicated as described above. This procedure is repeated for the other prolapsing 